\section{Studying anemia of chronic disease and iron deficiency in patients with rheumatoid arthritis by iron status and circulating hepcidin}

\author{
Warqaa Khalaf, ${ }^{1}$ \\ Haithem Ahmed Al-Rubaie, ${ }^{2}$ \\ Sami Shihab $^{3}$
}

${ }^{1}$ Al-Shatra General Hospital, Dhi Qar;

2Department of Pathology, and

${ }^{3}$ Department of Medicine, College of

Medicine, University of Baghdad,

Baghdad, Iraq

\section{Abstract}

Anemia of chronic disease (ACD) and iron deficiency anemia (IDA) are the two most important types of anemia in rheumatoid arthritis (RA). Functional iron deficiency in ACD can be attributed to overexpression of the main iron regulatory hormone hepcidin leading to diversion of iron from the circulation into storage sites resulting in iron-restricted erythropoiesis. The aim is to investigate the role of circulating hepcidin and to uncover the frequency of IDA in RA. The study included 51 patients with RA. Complete blood counts, serum iron, total iron binding capacity, ferritin, and hepcidin25 were assessed. ACD was found in $37.3 \%$ of patients, IDA in $11.8 \%$, and combined (ACD/IDA) in $17.6 \%$. Serum hepcidin was higher in ACD than in control and the other groups $(\mathrm{P} \leq 0.001)$. It was strongly and positively correlated with ferritin $(\mathrm{P}<0.001)$, while hemoglobin, serum iron, and total iron binding capacity were negatively correlated with hepcidin $(\mathrm{P}=0.016,0.022$ and $<0.001$, respectively). High serum hepcidin was significantly associated with ACD in RA. IDA alone or combined with ACD was encountered in about a third of patients.

\section{Introduction}

Rheumatoid arthritis (RA) is a progressive disease that can lead to joint deformity, destruction, and disability, with various manifestations. ${ }^{1}$ Disease activity score (DAS28) is usually used to monitor RA. ${ }^{2}$

Anemia is a common manifestation of RA that reduces quality of life, and increases morbidity. Anemia of chronic disease (ACD) is the most common cause of anemia occurring in patients with RA, however, iron deficiency (IDA) caused by gastrointestinal bleeding associated with drug treatment is also frequent and may coexist with ACD. ${ }^{3}$ Proinflammatory stimuli inhibit erythropoiesis and decreases the iron available for heme synthesis. Inflammationinduced increased levels of hepcidin reduce intestinal iron absorption and iron release from macrophages. This is done through interaction, internalization, and degradation of the cellular iron exporter ferroportin. Consequently, the total body iron content is normal, but less iron is available for erythropoiesis. ${ }^{4}$ Hepcidin is proposed to be a central regulator of intestinal iron absorption and iron recycling by macrophages. ${ }^{5}$

Ferritin is a major intracellular iron storage protein. Serum ferritin reflects the iron stores and results from leakage from tissue or intracellular fluids and in health there is a relationship between the two. Serum ferritin is an acute-phase reactant and there are gender differences, these make ferritin somewhat less than an ideal test for determining iron deficiency. ${ }^{6}$

In RA, systemic inflammation as reflected by elevated C-reactive protein (CRP) concentrations is generally considered to result from the effect of inflamed joint-derived IL-6 on the liver. ${ }^{7}$ Erythrocyte sedimentation rate (ESR) is also used as a marker of inflammation in patients with RA and for evaluation and monitoring disease activity. ${ }^{8}$ Aim of the study is to investigate the role of circulating hepcidin and to assess its correlations with iron status, DAS28 score, CRP and ESR and to uncover the frequency of IDA in patients with RA.

\section{Materials and Methods}

This case-control study included 51 patients (10 males and 41 females) with RA. All patients fulfilled both the 1987 revised criteria for the classification of RA of the American College of Rheumatology (ACR) hospital and the 2010 ACR/ European League Against Rheumatism criteria. ${ }^{1}$ All patients were on methotrexate treatment, folic acid and low dose steroid and all of them except one were on biological agent (anti-TNF $\alpha$ ). DAS28 measurements were assessed and calculated according to DAS28-ESR formula, ${ }^{2}$ using a calculator version 1.2.

Anemia was defined, according to the World Health Organization criteria, as a hemoglobin $(\mathrm{Hb})$ concentration of $<13 \mathrm{~g} / \mathrm{dL}$ for men and $<12 \mathrm{~g} / \mathrm{dL}$ for women. ${ }^{4}$ Classification of anemia types to ACD, IDA and combined ACD/IDA was based on the criteria mentioned by Van Santen and Worwood, ${ }^{4,9}$ as follows:

IDA is considered when transferrin sat-
Correspondence: Haithem Ahmed Al-Rubaie, Department of Pathology, College of Medicine, University of Baghdad, Baghdad, Iraq.

Tel.: +9647710014484

E-mail: haithemalrubaie@yahoo.com

Key words: Rheumatoid arthritis, Anemia, Hepcidin, Ferritin.

Acknowledgements: We would like to thank Dr. Nahla Ghanim, The Teaching Laboratories - Medical City for measuring hepcidin peptide level by ELISA.

Contributions: HAAR, design and planning of the study, critical appraisal of the manuscript, data analysis, and final approval of the script; SS, clinical diagnosis of RA patients, measuring disease-activity score 28 , review and approval of the final script; WK, sample collection, major part of laboratory work, drafting and approval of the manuscript.

Conflict of interest: the authors declare no conflict interest.

Funding: none

Received for publication: 11 April 2018

Revision received: 6 February 2019

Accepted for publication: 13 February 2019.

This work is licensed under a Creative Commons Attribution-NonCommercial 4.0 International License (CC BY-NC 4.0).

(C) Copyright H.A. Al-Rubaie et al., 2019

Licensee PAGEPress, Italy

Hematology Reports 2019; 11:7708

doi:10.4081/hr.2019.7708

uration percentage (TSAT\%) is $<16$ and serum ferritin $<30 \mathrm{ng} / \mathrm{mL}$ and CRP $<10$ $\mathrm{mg} / \mathrm{L}$ or ESR $<30 \mathrm{~mm} / 1^{\text {st }}$ hour. ${ }^{4,9}$

$\mathrm{ACD}$ is considered when TSAT $\%$ is $\geq 16$ and serum ferritin $\geq 100 \mathrm{ng} / \mathrm{mL}$ and $\mathrm{CRP} \geq 10 \mathrm{mg} / \mathrm{L}$ or $\mathrm{ESR} \geq 30 \mathrm{~mm} / 1^{\text {st }}$ hour.

IDA/ACD is considered when TSAT $\%$ is $<16$ and serum ferritin $<100 \mathrm{ng} / \mathrm{mL}$ and $\mathrm{CRP} \geq 10 \mathrm{mg} / \mathrm{L}$ or $\mathrm{ESR} \geq 30 \mathrm{~mm} / 1^{\text {st }}$ hour.

Active inflammation was considered when $\mathrm{CRP} \geq 10 \mathrm{mg} / \mathrm{L}$ and/or $\mathrm{ESR} \geq 30$ $\mathrm{mm} / \mathrm{1}^{\text {st }}$ hour. ${ }^{4}$ Patients' exclusion criteria included pregnant or lactating mother, any history of blood transfusion within the last 3 months, recent acute blood loss, hemolysis, menorrhagia and hemorrhoids, any signs or symptoms of renal, hepatic, endocrine, or malignant disease, presence of acute or chronic infections, and juvenile rheumatoid arthritis. Thirty normal healthy volunteers, age- and sex-matched, were enrolled in this study as a control group. Blood was withdrawn and auto-analyzed for complete 
blood counts, serum iron, total iron binding capacity, and ferritin. Hepcidin-25 and high sensitivity CRP (hs-CRP) were measured by enzyme-linked immunosorbent assay.

Statistical analysis: median and interquartile range (IQR) were used to describe the data. Mann-Whitney $U$ test was used to analyze data between groups. Pvalue used to calculate the difference among the groups using Kruskal-Wallis test non-parametric method. Spearman correlation was used to show the degree of correlation between hepcidin25 and other variables. P-values were considered significant if less than 0.05 .

\section{Results}

The mean age was $45.41 \pm 10.33$ years and the range was (23-65). According to the level of DAS28-ESR score, the majority of patients $(58.8 \%)$ had high disease activity (>5.1), 33.4\% had moderate activity (>3.2$\leq 5.1$ ) and only $7.8 \%$ showed low disease activity $(>2.6-\leq 3.2)$ whereas none had non-active disease. ACD was found in $37.3 \%(19 / 51)$ of patients, IDA in $11.8 \%$ $(6 / 51), \mathrm{ACD} / \mathrm{IDA}$ in $17.6 \%(9 / 51)$ and
$33.3 \%(17 / 51)$ of patients were non-anemic (NA) as shown in Figure 1. The lowest median $\mathrm{Hb}$ was seen in IDA patients followed by IDA/ACD and ACD (Table 1). The median level of mean cell volume (MCV) in ACD was lower than shown in control and NA groups and was higher than seen in IDA and ACD/IDA $(\mathrm{P}<0.001)$. The MCV showed highly significant differences when compared between the 3 types of anemia with the NA and control group (Table 2). Furthermore, the differences were also significant when $\mathrm{MCV}$ was compared between ACD and each of ACD/IDA and IDA ( $\mathrm{P}=0.016$ and 0.017 , respectively). The median levels of serum iron and transferrin saturation percentage were lowest and subnormal in ACD/IDA followed by IDA and were normal in control and NA groups $(\mathrm{P} \leq 0.001)$. The lowest median value of ESR was seen in IDA and hs-CRP was significantly higher in ACD when compared with all other groups $(\mathrm{P}<0.001)$ as illustrated in Table 3. NA group showed insignificant dif-
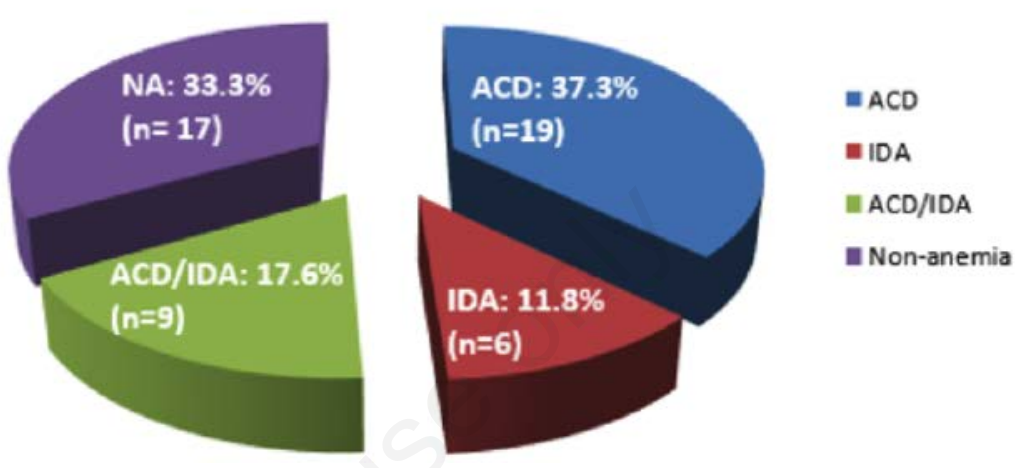

Figure 1. Anemia profile in 51 Rheumatoid arthritis patients.

Table 1. Hematological parameters and serum iron status in RA patients and control.

\begin{tabular}{|c|c|c|c|c|c|c|}
\hline \multirow{2}{*}{ Variables } & \multicolumn{4}{|c|}{ RA group ( $N=51)$} & \multirow[t]{2}{*}{ Control $(\mathrm{N}=30)$} & \multirow[t]{2}{*}{ P value* } \\
\hline & ACD (N=19) & IDA $(\mathrm{N}=6)$ & $\mathrm{ACD} / \mathrm{IDA}(\mathrm{N}=9)$ & $\mathrm{NA}(\mathrm{N}=17)$ & & \\
\hline $\mathrm{Hb}(\mathrm{g} / \mathrm{dL})$ & $11.5(2.2)$ & $9.9(1.3)$ & $10.2(1.4)$ & $12.7(0.9)$ & $13.3(2.6)$ & $<0.001$ \\
\hline MCV (fl) & $79.8(7.2)$ & $72.8(7)$ & $67.7(13.1)$ & $84(5)$ & $85(4.8)$ & $<0.001$ \\
\hline Iron $(\mu \mathrm{g} / \mathrm{dL})$ & $42(30)$ & $22(9)$ & $17(13.5)$ & $55(15)$ & $81.5(37.5)$ & $<0.001$ \\
\hline TSAT (\%) & $17.1(2.9)$ & $6(2.4)$ & $4.4(3.7)$ & $18.2(4.9)$ & $25.1(11.1)$ & $<0.001$ \\
\hline
\end{tabular}

*P values were calculated using Kruskal-Wallis test non parametric method. Data are presented as median and IQR.

Table 2. Comparison of the hematological parameters and iron status in the study population (P value).

\begin{tabular}{|c|c|c|c|c|c|c|c|c|c|}
\hline Variables & $\begin{array}{l}\mathrm{ACD} v s . \\
\mathrm{ACD} / \mathrm{IDA}\end{array}$ & $\begin{array}{c}\text { ACD } v s . \\
\text { NA }\end{array}$ & $\begin{array}{c}\text { ACD/IDA } u s . \\
\text { NA }\end{array}$ & $\begin{array}{l}\text { ACD vs. } \\
\text { control }\end{array}$ & $\begin{array}{c}\text { IDA } v s . \\
\text { NA }\end{array}$ & $\begin{array}{l}\text { ACD/IDA vs. } \\
\text { control }\end{array}$ & $\begin{array}{l}\text { NA } v s . \\
\text { control }\end{array}$ & $\begin{array}{l}\text { IDA } v s . \\
\text { control }\end{array}$ & $\begin{array}{c}\text { ACD } v s . \\
\text { IDA }\end{array}$ \\
\hline $\mathrm{Hb}(\mathrm{g} / \mathrm{dL})$ & 0.055 & $<0.001$ & $<0.001$ & $<0.001$ & $<0.001$ & $<0.001$ & 0.136 & $<0.001$ & 0.065 \\
\hline MCV (fl) & 0.016 & 0.006 & $<0.001$ & $<0.001$ & $<0.001$ & $<0.001$ & 0.006 & $<0.001$ & 0.017 \\
\hline Iron $(\mu \mathrm{g} / \mathrm{dL})$ & 0.001 & 0.012 & $<0.001$ & $<0.001$ & 0.001 & $<0.001$ & 0.001 & $<0.001$ & 0.002 \\
\hline TSAT (\%) & $<0.001$ & 0.526 & $<0.001$ & $<0.001$ & $<0.001$ & $<0.001$ & $<0.001$ & $<0.001$ & $<0.001$ \\
\hline
\end{tabular}

Table 3. Acute inflammatory markers and DAS 28 score in the study group ( $\mathrm{n}=\mathbf{8 1})$.

\begin{tabular}{|c|c|c|c|c|c|c|}
\hline \multirow[t]{2}{*}{ Variables } & \multicolumn{4}{|c|}{ RA group (N=51) } & \multirow{2}{*}{ Control $(\mathrm{N}=30)$} & \multirow[t]{2}{*}{ Pvalue* } \\
\hline & $\operatorname{ACD}(\mathrm{N}=19)$ & IDA $(\mathrm{N}=6)$ & ACD/IDA $(\mathrm{N}=9)$ & NA $(N=17)$ & & \\
\hline ESR (mm/1st $h r)$ & $61(23)$ & $25(15.9)$ & $50(29.5)$ & $34(22)$ & $9(3.3)$ & $<0.001$ \\
\hline CRP (mg/L) & $12.3(0.9)$ & $5.1(4)$ & $4.5(7.8)$ & $4.3(7.5)$ & $0.9(1.7)$ & $<0.001$ \\
\hline DAS (28 score) & $6.1(1.2)$ & $5.2(1.6)$ & $5.8(0.9)$ & $3.6(2.2)$ & - & 0.002 \\
\hline Ferritin (ng/mL) & $107(202.3)$ & $10.3(12.1)$ & $15.6(27.7)$ & $35.8(33.1)$ & $47(51.5)$ & $<0.001$ \\
\hline Hepcidin (ng/mL) & $35(43.9)$ & $4(2.8)$ & $4.5(6.9)$ & $8.9(11.4)$ & $5.7(5.1)$ & $<0.001$ \\
\hline
\end{tabular}

*Data are presented as median and IQR. 
Table 4. Comparison of acute inflammatory markers and DAS 28 score in 51 RA patients (P values).

\begin{tabular}{|c|c|c|c|c|c|c|c|c|c|}
\hline Variables & $\begin{array}{l}\text { ACD vs. } \\
\text { ACD/IDA }\end{array}$ & $\begin{array}{l}\text { ACD vs. } \\
\text { IDA }\end{array}$ & $\begin{array}{c}\mathrm{ACD} v s . \\
\text { NA }\end{array}$ & $\begin{array}{l}\text { ACD vs. } \\
\text { control }\end{array}$ & $\begin{array}{c}\mathrm{ACD} / \mathrm{IDA} \\
\text { NA }\end{array}$ & $\begin{array}{c}\text { ACD/IDA ws. } \\
\text { control }\end{array}$ & $\begin{array}{l}\text { IDA ws. } \\
\text { NA }\end{array}$ & $\begin{array}{l}\text { IDAvs. } \\
\text { control }\end{array}$ & $\begin{array}{l}\text { NAvs. } \\
\text { control }\end{array}$ \\
\hline ESR (mm/ $\left./ 1^{\text {sthr}}\right)$ & 0.49 & 0.002 & 0.005 & $<0.001$ & 0.022 & $<0.001$ & 0.039 & 0.003 & $<0.001$ \\
\hline CRP (mg/L) & 0.004 & 0.003 & 0.001 & $<0.001$ & 0.936 & 0.004 & 1 & 0.001 & $<0.001$ \\
\hline DAS28 score & 0.337 & 0.022 & 0.001 & - & 0.011 & - & 0.183 & - & - \\
\hline Ferritin (ng/mL) & $<0.001$ & $<0.001$ & $<0.001$ & 0.001 & 0.007 & 0.003 & 0.002 & 0.001 & 0.917 \\
\hline Hepcidin (ng/mL) & $<0.001$ & $<0.001$ & 0.001 & $<0.001$ & 0.063 & 0.726 & 0.007 & 0.361 & 0.003 \\
\hline
\end{tabular}

ferences in hs-CRP when compared with IDA or ACD/IDA (Table 4). Disease activity score 28 was higher in anemic subgroups than NA group ( $\mathrm{P}=0.002)$. The differences between ACD and ACD/IDA and between IDA and NA groups were statistically insignificant. In IDA and ACD/IDA groups, the ferritin levels were much less than in NA and control groups $(\mathrm{P} \leq 0.007)$. Serum hepcidin 25 median level in ACD was much higher than in control and the other RA groups, and in IDA and ACD/IDA groups the hepcidin levels were less than that in non-anemic and control groups with statistically significant differences $(\mathrm{P}<0.001)$.

Variables like ferritin, hs-CRP, DAS28, and ESR were strongly and positively correlated with hepcidin $(\mathrm{P}<0.001$ for each), while $\mathrm{Hb}$, serum iron, and total iron binding capacity were negatively correlated with hepcidin with P-values of $0.016,0.022$, and $<0.001$, respectively. Correlation between transferrin saturation percentage and serum hepcidin was statistically insignificant (Table 5).

\section{Discussion}

In the current study, the prevalence of anemia was $66.7 \%$ which is comparable to those reported by Song et al., ${ }^{10}$ Borah et al., ${ }^{11}$ Sabău et al. ${ }^{12}(66 \%, 64 \%$ and $70.4 \%$, respectively). This study excluded various causes of anemia such as hemolysis, pregnant and lactating mother, menorrhagia, hemorrhoids. Otherwise actual frequency of anemia in RA would be much higher.

ACD was observed in $55.9 \%(19 / 34)$ of anemic patients. This finding is consistent with results of Sabău et al., ${ }^{12}$ and Borah et al., ${ }^{11}$ who found that ACD in anemic RA patients is present in $(52.6 \%$ and $60 \%$, respectively). This reflects the fact that ACD is the commonest type of anemia in RA. ${ }^{11}$ About $17.6 \%(6 / 34)$ of RA anemic patients had solely IDA which is mainly related to steroid and non-steroidal antiinflammatory drug use that causes occult gastrointestinal blood loss. ${ }^{13}$

In these cases, it also linked with dietary iron deficiency or malabsorption. Majority

Table 5. Correlation of serum hepcidin with some variables in 51 RA patients.

\begin{tabular}{lcc} 
& Spearman Correlation & P-values \\
Hepcidin $(\mathrm{ng} / \mathrm{mL})$ & 1 & - \\
Ferritin $(\mathrm{ng} / \mathrm{mL})$ & 0.69 & $<0.001$ \\
\hline HsCRP $(\mathrm{mg} / \mathrm{L})$ & 0.619 & $<0.001$ \\
DAS 28 score & 0.535 & $<0.001$ \\
\hline ESR $\left(\mathrm{mm} / \mathrm{l}^{\text {sthr }}\right)$ & 0.513 & $<0.001$ \\
Hb $(\mathrm{g} / \mathrm{dL})$ & -0.266 & 0.016 \\
\hline Iron $(\mu \mathrm{g} / \mathrm{dL})$ & -0.255 & 0.022 \\
TIBC $(\mu \mathrm{g} / \mathrm{dL})$ & -0.587 & $<0.001$ \\
\hline
\end{tabular}

of our RA patients are females whom as a consequence of menstrual bleeding, may suffer from IDA. ${ }^{14}$ It is important to identify ACD with concomitant IDA in RA since patients would benefit symptomatically from iron therapy. Treatment with iron in RA patients without iron deficiency may aggravate arthritic symptoms and may fail to manage anemia. ${ }^{3}$ About $26.5 \%(9 / 34)$ of anemic RA patients had IDA and ACD at the same time, and this was comparable to the study of van Santen et al., ${ }^{4}$ who found $8 / 40(20 \%)$ of RA patients have concurrent IDA/ACD. Patients in ACD group had higher median $\mathrm{Hb}, \mathrm{MCV}$, and serum iron levels than those in IDA and ACD/IDA groups. These findings are to some extent congruent with the study conducted by Sabău et al. ${ }^{15}$ which showed RA with ACD had higher $\mathrm{Hb}$ levels than RA with ACD/IDA. These results were similar to the work of Santen et al. ${ }^{4}$ Chronic disease anemia is classically mild anemia associated with low serum iron and high or normal serum ferritin levels. ${ }^{16}$

The median ESR value in ACD was the highest, however, the difference between ACD and ACD/IDA was statistically insignificant. This is in agreement with the studies of Santen et al. ${ }^{4}$ and Sabău et al. ${ }^{12,15}$

The CRP was significantly higher in ACD when compared with the other groups. Similar findings were reported by van Santen et $a l .{ }^{4}$ and Săbau et al. ${ }^{12}$ that revealed statistically significant differences in CRP between anemic group and NA group. Emeraha et al. ${ }^{17}$ also found that ESR and CRP were higher in RA patients with anemia than NA patients. Hs-CRP was raised in RA groups when compared with control, similar to results reported by van Santen et al. ${ }^{4}$ and Shrivastavaa et al. ${ }^{18}$

DAS28 score was significantly higher in the $\mathrm{ACD}$ and $\mathrm{ACD} / \mathrm{IDA}$ versus $\mathrm{NA}$ groups whereas there was no significant difference between ACD and ACD/IDA or between IDA and NA. These findings are consistent with those of Basak et al. ${ }^{3}$ who revealed a statistically significant difference between ACD and NA patients and reported insignificant difference between ACD alone and ACD with co-existent IDA patients. This may be due to smaller scale of the study and the interruption of disease activity by intake of multiple drugs. Patients from anemic subgroups ACD, ACD/IDA have more severe disease than patients from NA group as reflected by CRP, ESR and DAS28 score. ${ }^{12}$ The presence of IDA in RA patients was associated with a lower ESR value and subsequent lower DAS 28 score. Serum hepcidin in RA patients with ACD and NA was higher than in control and this was statistically significant. This was similar to the study of Dagli et al. ${ }^{19}$ who found significantly higher serum prohepcidin and hepcidin levels in patients with RA compared to healthy controls. Hepcidin 25 also showed the highest value in ACD compared with ACD/IDA, IDA, NA groups and control, and was statistically significant. Similar results were obtained by van Santen et al., ${ }^{4}$ Demirag et al., ${ }^{20}$ and Abdel-Khalek et $a l .{ }^{21}$ In the current study, the lowest hepcidin median level was found in IDA RA 
group where hepcidin suppression leads to induction of iron absorption from the gut, and therefore, it is a potential biomarker to assess iron deficiency in patients with inflammatory conditions. ${ }^{4}$

The study demonstrated that in the 51 RA patients, hepcidin 25 concentration was positively correlated with ESR, CRP and DAS28. This result is in agreement with studies done by Sabău et al., ${ }^{15}$ AbdelKhalek et al., ${ }^{21}$ Sellam et al., ${ }^{22}$ and Song et al. ${ }^{10}$ There is also a positive strong correlation between hepcidin 25 and ferritin, similar to findings by Osman et al. ${ }^{23}$ and Song et al. ${ }^{10}$ indicating that hepcidin is a useful biomarker for detection of active inflammation and it reflects disease activity of RA patients. An inverse correlation was shown between hepcidin 25 and $\mathrm{Hb}$, similar results were reported by Demirag et $a .^{20}$ and Sabău et al. ${ }^{15}$ The serum hepcidin level is found to be a significant predictor for $\mathrm{Hb}$ level. Hepcidin concentration was significantly and inversely correlated with serum iron, a result which is comparable to the study of Sabău et al. ${ }^{15}$ It is found that experimental hepcidin increase in humans, induced by IL- 6 infusion, is accompanied by a decrease in serum iron levels. ${ }^{20}$ Swellam et al. ${ }^{24}$ found that hepcidin is significantly correlated with laboratory anemia profile indicating that hepcidin binds to, and degrades ferroportin, thus reduces intestinal absorption of iron and blocks mobilization of iron from macrophages and hepatocytes, causing low serum iron and anemia through decreased iron reutilization.

The study showed a negative correlation between hepcidin 25 and TIBC, in agreement with results from Isaacs et al., ${ }^{25}$ who suggested that at baseline, hepcidin levels were inversely correlated with TIBC, underscoring the role of hepcidin in reducing iron bioavailability.

\section{Conclusions}

In conclusion, ACD is the most commonly encountered type of anemia in RA patients, however, IDA alone or combined with ACD was present in about a third of patients. Low serum hepcidin 25 is a potential biomarker to assess iron deficiency in RA patients and high levels reflect disease activity and is a significant predictor for a lower $\mathrm{Hb}$ level.

\section{References}

1. Harris Jr ED, Firestein GS. Clinical features of rheumatoid arthritis. In: Harris ED, Ruddy S, Budd RC (eds.). Kelley's textbook of rheumatology. 9th ed.
Philadelphia: Elsvier Saunders. 2013; 1109-28.

2. Nielung L, Christensen R, DanneskioldSamsøe B, et al. Validity and agreement between the 28-joint disease activity score based on $\mathrm{C}$ reactive protein and erythrocyte sedimentation rate in patients with rheumatoid arthritis. Arthritis 2015; 6.

3. Basak TB, Talukder SI. Anemia of chronic disease in rheumatoid arthritis and its relationship with disease activities. Dinajpur Med Col 2013;6:113-22.

4. Van Santen S, Van Dongen-Lases EC, de Vegt F, et al. Hepcidin and hemoglobin content parameters in the diagnosis of iron deficiency in rheumatoid arthritis patients with anemia. Arthritis Rheum 2011;63:3672-80.

5. Nemeth E, Valore EV, Territo M, et al. Hepcidin, a putative mediator of anemia of inflammation, is a type II acute-phase protein. Blood 2003;101:7.

6. Wish JB. Assessing iron status: beyond serum ferritin and transferrin saturation. Clin J Am Soc Nephrol 2006;1:S4-8.

7. Dessein PH, Gonzalez-Gay MA, Woodiwiss AJ, et al. The impact of the metabolic syndrome on cardiovascular risk and disease in rheumatoid arthritis. Future Rheumatol 2008;3:335-49.

8. Wener MH. Autoantibodies and other laboratory tests. In: St.chair EW, Pisetsky DS, Haynes BF (eds.). Rheumatoid arthritis. USA: Lippincott William and Wilkins 2004; 65-79.

9. Worwood M, May A. Iron deficiency anemia and iron overload. In: Bain BJ, Lewis SM, Bates I, Laffan MA (eds). Dacie and Lewis Practical Haematology. 11th ed. Philadelphia: Churchill Livingstone 2011; 175-200.

10. Song SN, Iwahashi M, Tomosugi N, et al. Comparative evaluation of the effects of treatment with tocilizumab and TNF- $\alpha$ inhibitors on serum hepcidin, anemia response and disease activity in rheumatoid arthritis patients. Arthritis Res Ther 2013;15:R141.

11. Borah DJ, Iqbal F. Anemia in recent onset rheumatoid arthritis. JK Science 2007;9:120-2.

12. Sabău A, Crăciun AM, Gabriela $C$, et al. Association between acute phase reactant levels, and disease activity score (DAS28), in patients with rheumatoid arthritis and anemia. Revista Română de Rheumatologie 2011;20:225-9.

13. Matsui T, Kuga Y, Kaneko A, et al. Disease activity score 28 (DAS28) using $C$ reactive protein underestimates disease activity and overestimates EULAR response criteria compared with DAS28 using erythrocyte sedimentation rate in a large observational cohort of rheumatoid arthritis patients in Japan. Ann Rheum Dis 2007;66:1221-6.

14. Weiss G, Schett G. Anemia in inflammatory rheumatic diseases. Nat Rev Rheumatol 2013;9:205-15.

15. Sabău A, Văleanu M, Bolosiu HD, Crăciun AM. Evaluation of serum hepcidin variation in patients with rheumatoid arthritis according to anemia profile and its correlation with disease activity. Revista Română de Medicină de Laborator 2013;21:17-27.

16. Cullis JO. Diagnosis and management of anemia of chronic disease: current status. Br J Haematol 2011;154: 289-300.

17. Emeraha A, Abbasa SF, Pashab HF. Serum prohepcidin concentrations in rheumatoid arthritis and its relation to disease activity. Egypt Rheumatol Rehabil 2014;41:130-4.

18. Shrivastavaa AK, Singhb HV, Raizadac A, et al. Inflammatory markers in patients with rheumatoid arthritis. Allergol Immunopathol (Madr) 2014;582:7.

19. Dagli M, Yilmaz S, Sivrikaya A, Ozturk B. Serum prohepcidin and hepcidin levels in patients with rheumatoid arthritis: a prospective study. Turkiye Klinikleri J Med Sci 2013;33:946-50.

20. Demirag MD, Haznedaroglu S, Sancak $\mathrm{B}$, et al. Circulating hepcidin in the crossroads of anemia and inflammation associated with rheumatoid arthritis. Intern Med 2009;48:421-6.

21. Abdel-Khalek MA, El-Barbary AM, Essa SA, Ghobashi AS. Serum hepcidin: a direct link between anemia of inflammation and coronary artery atherosclerosis in patients with rheumatoid arthritis. J Rheumatol 2011;38:2153.

22. Sellam J, Kotti S, Fellahi S, et al. Serum hepcidin level is not an independent surrogate biomarker of disease activity or of radiographic progression in rheumatoid arthritis: results from the ESPOIR cohort. Ann Rheum Dis 2013;72:312-4.

23. Osman KS, Aly LH, Abd El-Hamid WM, Tawfik MR. Role of hepcidin in the pathogenesis of anemia not caused by iron deficiency. J Clin Cell Immunol 2014;5:1-22.

24. Swellam M, Abu Gabal KM, Youssef SS. Interleukin-1 receptor antagonist gene polymorphism and hepcidin in rheumatoid arthritis: correlations with clinical and laboratory indices of disease activity. IUBMB Life 2013;65:883-8.

25. Isaacs JD, Harari O, Kobold U, et al. Effect of tocilizumab on haematological markers implicates interleukin-6 signalling in the anaemia of rheumatoid arthritis. Arthritis Res Ther 2013;15:R204-2. 